\title{
GESTÃO ECONÔMICA DE INVESTIMENTOS EM ATIVOS FIXOS ${ }^{1}$
}

\author{
Armando Catelli \\ Professor Doutor do Departamento de Contabilidade e Atuária da FEA/USP \\ Fundador e coordenador do Núcleo GECON \\ Cláudio Parisi \\ Professor de pós-graduação da FECAP \\ Mestre e Doutor em Controladoria e Contabilidade pela FEA/USP \\ Pesquisador do Núcleo GECON.
}

\section{Edilene Santana Santos \\ Professora das Faculdades IBMEC}

RESUMO

Num ambiente global de intensas mudanças competitivas, a mensuração dos ativos, especificamente dos ativos fixos, requer a superação da rigidez dos custos históricos e da depreciação linear, próprios da contabilidade tradicional, e a adoção de critérios que permitam avaliar adequadamente a realidade econômica desses ativos. Partindo da premissa de que o patrimônio líquido deve representar o valor da empresa, e de que sua variação expressa o resultado econômico, o Sistema de Gestão Econômica - Gecon conceitua e mensura os ativos fixos pelo valor presente dos seus benefícios futuros para a empresa. Como sistema de gestão voltado para decisões econômicas, o Gecon explicita um modelo de decisão para o evento investimento em ativos fixos. Nessa decisão são considerados os custos diretos dela decorrentes, bem como os benefícios econômicos resultantes do uso do ativo fixo pela empresa, mensurados pelo seu custo de oportunidade. Considerando a empresa como conjunto de áreas de responsabilidade conceituadas como centros de resultado, o Gecon identifica a contribuição de cada área envolvida na decisão para a obtenção do resultado econômico do investimento e, portanto, para o resultado da empresa. O fluxo de resultados do investimento é gerenciado durante toda a sua vida útil, desde o momento da tomada de decisão inicial até o momento final da decisão de desativação ou desinvestimento.

Palavras-chave: ativo fixo, investimento, gestão econômica, custo de oportunidade, contabilidade gerencial.
In a global environment that is going through intense competitive changes, the measurement of assets, specifically fixed assets, makes it necessary to overcome the rigidity of historical costs and straightline depreciation, characteristic of traditional accounting, and to adopt criteria that allow for the adequate evaluation of the economic reality of these assets. Starting from the premise that net equity must represent company value and that its variation expresses economic income, the Economic Management System-Gecon-conceptualizes and measures fixed assets by the present value of their future benefits for the company. As a management system directed towards economic decisions, Gecon formulates a decision model for the investment event in fixed assets. In this decision, the resulting direct costs are considered, as well as the economic benefits that result from the use of the fixed asset by the company, which are measured at their opportunity cost. Considering the company as a set of responsibility areas that are conceived as result centers, Gecon identifies the contribution of each area involved in the decision to the economic income of the investment and, consequently, to company income. The income flow of the investment is managed throughout its useful life, from the initial decision-making moment until the final moment of the deactivation or divestment decision.

Keywords: fixed asset, investment, economic management, opportunity cost, management accounting. 


\section{INTRODUÇÃO}

Em 1993 a empresa Pratt \& Whitney, uma das maiores fabricantes de motores de aviões do mundo, contratou consultores japoneses para renovar os seus processos industriais. Um dos resultados da introdução do novo processo de "produção enxuta" foi que vários equipamentos de alta tecnologia - entre os quais uma enorme máquina revestidora de pás de turbinas, de última geração, no valor de 80 milhões de dólares - tiveram que ser abandonados, cedendo lugar a outros, não tão sofisticados, mas que aumentaram a produtividade, flexibilidade e lucratividade da empresa (Womack \& Jones, 1998, p.165-208).

Alguns anos antes, como menciona Peter Drucker (1992, p. 205), a General Motors havia investido "no mínimo 30 bilhões, talvez 40 bilhões de dólares em automação", mas tal investimento, que tornaria sua linha de montagem mais eficiente, de fato tornou-a menos flexível e seus custos de mãode-obra, ao invés de se reduzirem, aumentaram para $28 \%$, contra $15 \%$ da Ford e $16 \%$ da Toyota nos Estados Unidos (id. p. 220).

Ninguém poderá negar que nos dois exemplos acima os investimentos em ativos fixos foram precedidos de cuidadosos procedimentos de avaliação e mensuração. Mas tudo indica que tal análise não deve ter considerado todos os aspectos relevantes de tais investimentos.

É evidente que o êxito ou fracasso de um investimento não pode ser atribuído exclusivamente ao seu método de mensuração. Contudo, os exemplos acima e muitos outros mostram que os sistemas de mensuração se diferenciam pela capacidade maior ou menor de atingir, no processo de decisão empresarial, a realidade econômica subjacente, da qual depende o sucesso ou o fracasso dos investimentos.

Nesse sentido, as deficiências da contabilidade de custos tradicional vêm sendo identificadas há muitos anos, tendo sido até mesmo responsabilizadas pela perda de competitividade das empresas americanas na década de $80^{2}$. Assim, em 1987, Johnson \& Kaplan publicaram o hoje clássico Relevance Lost, embora sua acuidade na crítica à contabilidade tradicional não tenha sido pelos próprios autores acompanhada de uma superação radical das deficiências que recuperasse satisfatoriamente a relevância perdida. ${ }^{3}$

Em 1990 Peter Drucker, ao projetar parâmetros futuros da administração, preconizou "uma nova contabilidade de manufatura, que seria melhor chamada de 'economia da manufatura' [e que] difere radicalmente da contabilidade de custos tradicional em seus conceitos básicos. Seu propósito é integrar a manufatura com a estratégia de negócios" (id. p. 202).

Dentro das mesmas preocupações, desde o final dos anos 70, na Universidade de São Paulo, o Prof. Armando Catelli dirigia suas reflexões para a superação das insuficiências da contabilidade de custos tradicional diante das necessidades de informação da gestão empresarial e da lógica do processo decisório. Como resultado de sua experiência como executivo e consultor de empresas, unida a seu pendor de investigação, foram desenvolvidos, junto ao Programa de Pós-Graduação em Controladoria e Contabilidade da FEA/USP (Faculdade de Economia, Administração e Contabilidade da Universidade de São Paulo), os princípios, conceitos e procedimentos do Sistema de Gestão Econômica - Gecon.

$O$ intenso interesse dessa abordagem da contabilidade gerencial se mostra nos mais de 80 trabaIhos publicados até o presente, entre teses de doutoramento e de livre docência, dissertações, livros e numerosos artigos científicos, bem como em contínua atividade de consultoria empresarial.

Este trabalho, na linha da Gestão Econômica, parte da constatação de que no ambiente econômico atual, de crescente competitividade em escala global e intensas mudanças tecnológicas e de mercado, a adequada mensuração dos ativos para tomada de decisão empresarial exige a superação da rigidez e estática dos conceitos contábeis tradicionais, baseados em custos históricos e depreciação linear.

Assim, este trabalho tem por objetivo apresentar princípios e critérios de mensuração mais flexíveis e relevantes, que possam promover o gerenciamento eficaz dos investimentos da empresa, particularmente

${ }^{2}$ Thomas Pryor escreveu em 1988 na Business Week: “A contabilidade de custos está afundando as empresas americanas. Se quisermos nos manter competitivos, temos que mudar (nossos sistemas de custos).” (Apud Shank \& Govindarajan, 1997, p.IX).

${ }^{3}$ Para uma abordagem crítica do ABC - Activity Based Costing, ver Catelli \& Guerreiro (1994, p.322-328). 
em ativos fixos. Para tal, inicialmente, será mostrado como os princípios do Gecon se aplicam a todas as atividades da empresa.

A visão da empresa, no seu todo, como investimento, não será aqui detalhada. Mas, os critérios de avaliação de ativos, adotados pela gestão econômica, são os mesmos que regem o mercado de capitais na valoração das empresas do ponto de vista do investidor, sobretudo a adoção do fluxo de caixa descontado .

Com efeito, como demonstraram os Prêmios Nobel Franco Modigliani e Merton Miller, é a valoração contábil das empresas sob critérios econômicos - e, dentro de certos limites, não a sua estrutura financeira e de capital e nem sequer a distribuição de dividendos - que representa o seu valor relevante, o seu valor efetivo, de mercado:

"That [market] value, according to M\&M [Modigliani \& Miller] is determined solely by corporate investment and operating decisions, by those 'real decisions' that produce the firms operating cash flows. (More precisely, the value of the firm was formulated by M\&M as the discounted present value of 'future cash flows from the firm present assets and future growth opportunities' net of 'the additional investment necessary to initiate and sustain those flows')" (Chew, 1993, p. xii).

\section{A GESTÃO ECONÔMICA DA EMPRESA}

A Gestão Econômica busca, simultaneamente, contribuir para o desenvolvimento da ciência contábil e responder às necessidades atuais das empresas, desenvolvendo uma visão metodologicamente consistente e abrangente, que enfoca a organização sob os aspectos operacional-estrutural, econômico e gerencial de suas atividades. Procura, desse modo, recuperar a relevância da informação contábil mediante a tradução de princípios teóricos rigorosos em modelos praticáveis pelos gestores das empresas.

Como sistema gerencial, a Gestão Econômica se caracteriza por uma visão holística da empresa, pela mensuração por conceitos econômicos de mercado e pelo enfoque na gestão de negócios, centrada nas decisões tomadas em cada evento empresarial.

\subsection{A Empresa como Sistema}

A visão holística consiste na visão da empresa como um todo sistêmico, composto de elementos interdependentes e integrados na busca de um objetivo comum: a eficácia da organização. Essa visão contrasta com a visão linear e funcionalista tradicional do taylorismo, que dividia as empresas em unidades compartimentadas, estruturadas por um comando centralizado. Na visão sistêmica, as tradicionais áreas funcionais são consideradas nas suas interações entre si e com o ambiente, mediante os subsistemas que compõem o todo sistêmico da organização.

"Através do desempenho de suas funções, a empresa encontra-se em um processo interativo contínuo com o meio ambiente, obtendo recursos, transformando-os em produtos e atendendo aos seus objetivos. Esse processo desenvolve-se a partir da interação entre seus subsistemas, ou seja, as pessoas (subsistema social), condicionadas por determinados princípios (subsistema institucional), ocupando determinados postos com autoridade e responsabilidade pré-definidas (subsistema formal), tomam decisões (subsistema de gestão) sobre recursos (subsistema físico), utilizando informações (subsistema de informação), para que a empresa alcance seu objetivo" (Guerreiro, 1989, p.154).

Desse modo, todas as atividades da empresa são consideradas sistêmicas, consistindo em interações entre os diversos subsistemas da empresa.

Assim, a compreensão do sistema não pode ser obtida mediante a análise de suas partes separadamente.

"Com efeito, não é da mera soma das partes que se constitui o sistema, mas sim, das conexões e interações entre os seus elementos, das quais resulta para o conjunto algo de novo e único, que não está contido em cada uma de suas partes isoladamente.

A abordagem sistêmica tem, portanto, como ponto de partida, esse resultado novo que surge da interação dos elementos do siste- 
ma. Éa partir do todo, resultante da integração das partes, que essas mesmas partes podem ser conceituadas e identificadas nas suas diversas funções e interações" (Santos \& Ponte, 1998, p.708).

A Gestão Econômica, dentro da visão sistêmica, considera a empresa como um conjunto orgânico de áreas de responsabilidade, cujos gestores tomam decisões com vista ao resultado global da organização. As áreas de responsabilidade, que podem ou não coincidir com as tradicionais áreas funcionais, são consideradas centros de resultado, contribuindo para a formação do resultado do todo sistêmico.

A visão sistêmica se aplica igualmente à conceituação dos ativos, em particular dos ativos fixos, objeto deste trabalho.

Assim, não só o conceito genérico de ativo fixo, como cada elemento concreto integrante do ativo, como uma máquina ou um imóvel, só pode ser compreendido em função do que representa para o todo sistêmico da empresa. Os ativos fixos, como elementos do subsistema físico da empresa, são considerados nas suas interações com os outros subsistemas, mediante as quais são valorados. 0 tipo de imóvel, sua localização, as máquinas e equipamentos, certamente representam maior ou menor importância ou valor, na medida em que contribuem para a consecução dos objetivos do todo da empresa, para a realização de sua missão, para suas estratégias de produtos e mercados, para as decisões das pessoas envolvidas em razão de seus cargos e funções, e muitas outras interações sistêmicas.A Figura 1 representa o sistema empresa, seu fluxo produtivo e respectivos ativos do subsistema físico, em interação com os demais subsistemas e com o macro-sistema ambiental ${ }^{4}$.

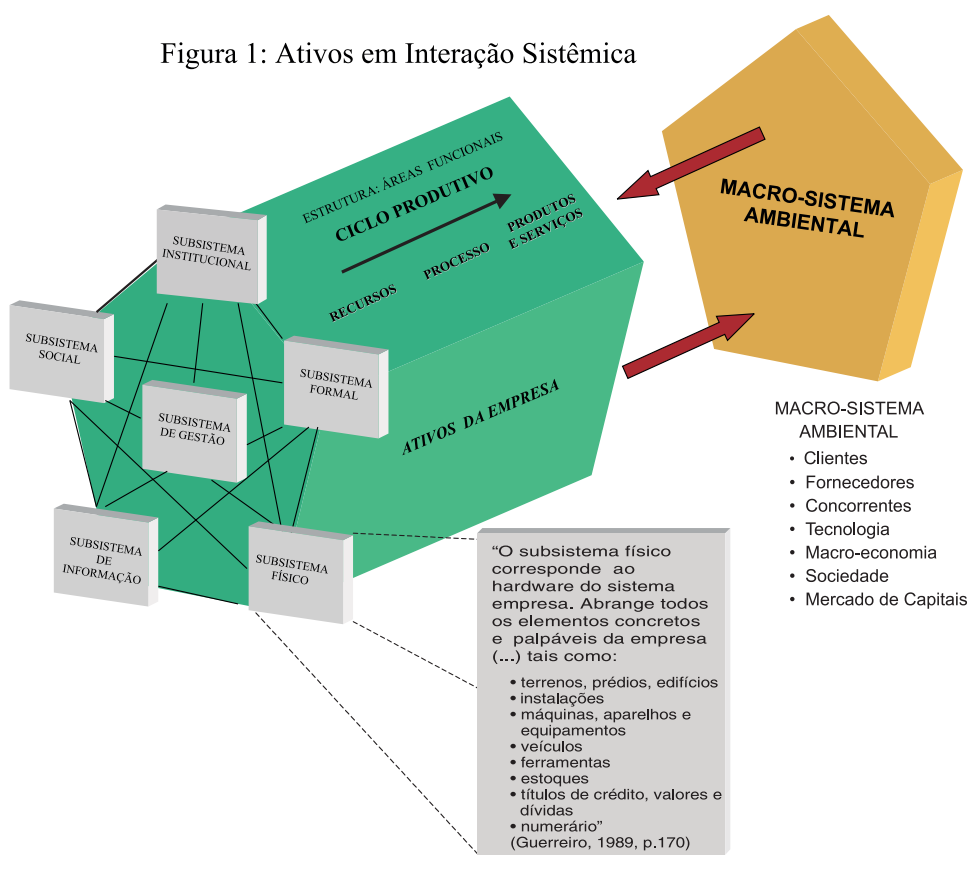

Será a seguir examinada a adoção de critérios econômicos de mercado na valoração do lucro e dos ativos na Gestão Econômica.

\footnotetext{
4 "Neste contexto, o subsistema físico corresponde ao ferramental que pessoas (subsistema social), com determinada autoridade e responsabilidade (subsistema formal), municiadas das informações necessárias (subsistema de informações) e condicionadas por determinados princípios (subsistema institucional), interagem no processo de tomada de decisões (subsistema de gestão). Através da interação desses subsistemas são executadas as funções empresariais (compra, venda, finanças ,etc.), no sentido de a empresa cumprir a sua missão" (Guerreiro, 1989, p.170-171).
} 


\subsection{Mensuração por Critérios Econômicos de Mercado}

Desde a década de 60, muito se tem discutido sobre a validade dos princípios adotados pela contabilidade na produção da informação. No final da década de 80, Johnson \& Kaplan (1987) em Relevance Lost, mostraram quão pouco se tem progredido no desenvolvimento de conceitos e práticas contábeis adequadas à gestão dos negócios.

O foco principal da maioria das críticas efetuadas está na falta de solidez dos princípios contábeis adotados. Como afirmam Hendriksen \& Van Breda (1992, p. 126) o grande problema da ênfase dada pelo processo contábil e da estrutura dos relatórios convencionais é que termos contábeis, como lucro líquido e receita, e métodos de mensuração, como o custo histórico, têm pouco ou nenhum significado em relação aos fenômenos do mundo real.

Para Philips (1963, p.697), a maioria dos problemas que os contadores têm para desenvolver práticas contábeis julgadas sólidas está no inevitável conflito decorrente da necessidade de números que sejam ao mesmo tempo realísticos e objetivamente mensuráveis.

Consciente dessa tensão constante entre a objetividade e relevância da mensuração contábil, a Gestão Econômica adota os critérios que, simplesmente, vigoram no mundo econômico e que incorporam tanto a objetividade refletida nas transações que criam riqueza efetiva, como os aspectos de subjetividade $e$ projeções sobre o futuro, inerentes a todos os relacionamentos humanos, em particular aos negócios.

Desde o início dos esforços de se medir a riqueza, a economia e a contabilidade se concentraram nas mudanças patrimoniais dos empreendimentos, como já consta nos inventários e balanços antigos. Assim, já em 1546, Gottlieb "usou uma demonstração resumida ${ }^{5}$ (ativos à esquerda e passivos e capital anterior à direita) para mostrar que a diferença entre os totais é o cálculo do lucro, o qual quando adicionado ao lado menor produz novos totais iguais". Tratava-se, com efeito, de um dos primeiros balanços conhecidos (Litleton \& Zimmerman, 1962, p.78).
Desde as origens até hoje, como destacou Irwing Fisher, o capital é considerado um estoque de riqueza e o lucro um fluxo de benefícios gerados pelo capital. Adam Smith e, mais recentemente, Hicks consideram tais benefícios como lucro apenas na medida em que excedam o valor de manutenção do capital. ${ }^{6}$

A questão surge na medida em que a contabilidade, pressionada pelos conceitos de lucro distribuível e tributável, se concentra em critérios conservadores e objetivos que mensuram o patrimônio pelos valores nominais do custo histórico, reconhecendo ganhos e lucros apenas quando realizados pela venda. Restringe-se, assim, a capacidade de mensurar, tanto o fluxo de benefícios que constitui o lucro, como o valor do patrimônio, do capital da empresa, como fonte desses benefícios. Esse desvirtuamento em nome da objetividade conduz a informações que se afastam da realidade - perdendo justamente a objetividade - capazes, por exemplo, de produzir perfis patrimoniais de empresas com valor muito superior ao que lhes é atribuído pelo mercado de capitais.

A Gestão Econômica, como visão de negócios, adota os critérios econômicos de mercado para a mensuração do lucro e do valor do patrimônio da empresa. Tais valores são inseparáveis, uma vez que o lucro é o benefício gerado pelo patrimônio, além do necessário para manter esse patrimônio intacto e o patrimônio, por sua vez, é mensurado pelo fluxo dos benefícios futuros que pode gerar, reduzidos ao valor presente.

Assim, comenta Guerreiro (1992, p.5):

"Em termos econômicos, o lucro é visto como a quantia máxima que a firma pode distribuir como dividendos e ainda continuar tão bem ao final do período como estava no começo. Continuar tão bem, economicamente falando, é interpretado como manter o capital intacto em termos do valor descontado do fluxo de recebimentos líquidos futuros. O lucro econômico é gerado, portanto, assim que exista um aumento no patrimônio líquido. Por outro lado, para mensurar o lucro como incremento do

${ }^{5}$ Demonstração resumida é uma tradução livre para summary account.

${ }^{6}$ Ver Irving Fisher, apud Hendriksen \& Van Breda (1992, p.279-283). Ver também Guerreiro (1989, p.185-187). 
patrimônio líquido é necessária a avaliação de todos os ativos da empresa com base nos recebimentos líquidos futuros esperados. O lucro é mensurado através do crescimento do patrimônio líquido originado pela manipulação dos ativos. Sob esse prisma, os ativos de qualquer natureza são "recebíveis" esperados para fluir para a empresa período a período".

Do mesmo modo, Martins (1972, p.30) considera "o potencial de resultado econômico a verdadeira caracterização de um elemento como ativo, e não só isso, considerâmo-lo como sendo ele próprio o real ativo de uma entidade".

Quadro 1 sintetiza as principais diferenças entre os critérios econômicos e os adotados tradicionalmente pela contabilidade.

Dentro dessa conceituação, todas as atividades da empresa até o nível mínimo das transações, são efetuadas segundo critérios econômicos. Assim, todas as decisões dos gestores são escolhas entre variáveis de mercado, tanto nas transações internas como nas externas. Com efeito, o conceito de lucro, como fluxo dos benefícios a partir dos ativos da empresa, não ocorre apenas na venda, mas é gerado progressivamente, nas diversas fases do ciclo produtivo, sendo mensurado na Gestão Econômica mediante transações entre as áreas de responsabilidade, entre essas e o mercado, bem como por impactos de alterações do ambiente sobre o patrimônio da empresa, independentes das decisões dos seus gestores, ou seja, os chamados impactos tempo-conjunturais ${ }^{7}$.

Para mensurar os resultados progressivos dessas transações, a Gestão Econômica adota critérios como preços de transferência baseados no custo de oportunidade, cujo conceito passase brevemente a examinar, conforme Catelli \& Santos (2001, pp. 6-8).

\section{Quadro 1: Lucro Contábil versus Lucro Econômico}

\begin{tabular}{|c|c|}
\hline LUCRO CONTÁBIL & LUCRO ECONÔMICO \\
\hline Maior objetividade & Maior subjetividade \\
\hline Os ativos são avaliados na base de custos originais. & $\begin{array}{l}\text { Os ativos são avaliados pelo valor presente do fluxo de } \\
\text { benefícios futuros. }\end{array}$ \\
\hline Ênfase em custos. & Ênfase em valores. \\
\hline Os ganhos são reconhecidos apenas na realização pela venda. & $\begin{array}{l}\text { Reconhecimento de ganhos quando identificados nos ativos, } \\
\text { com base no mercado. }\end{array}$ \\
\hline $\begin{array}{l}\text { Não se efetuam ajustes em função de mudanças nos níveis de } \\
\text { preços dos bens na economia. }\end{array}$ & $\begin{array}{l}\text { São efetuados ajustes devidos a mudanças nos níveis de preços } \\
\text { dos bens na economia. }\end{array}$ \\
\hline Não reconhecimento do "Goodwill". & Reconhecimento do "Goodwill”. \\
\hline Utilização de regras e de critérios tradicionais. & Utilização de regras e critérios econômicos. \\
\hline
\end{tabular}

Fonte: adaptado de Guerreiro (1992, p.196-197).

\footnotetext{
${ }^{7}$ Ver, sobre eventos tempo-conjunturais, Barros \& Nossa (1998, 51-66).
} 


\subsection{O Custo de Oportunidade na Gestão Econômica}

O "homo oeconomicus" existe num mundo escasso e isso faz com que o seu comportamento racional seja sempre uma escolha entre diferentes alternativas. A aceitação de uma alternativa necessariamente exclui ou sacrifica outras. O benefício excluído é considerado pelos economistas como uma perda de oportunidade e denominado "custo de oportunidade" da decisão. Como Heymann \& Bloom (1990, p. xi) observam - estranhando que um conceito de 200 anos de idade não tenha ainda sido totalmente compreendido - "o conceito de custo de oportunidade e sua mensuração estão estreitamente associados à teoria da escolha, ao conceito de valor e à estrutura da tomada racional de decisões".

ljiri (1967, p. 34 ss) ilustra a decisão básica de valor com o simples exemplo do homem que vive sozinho numa cabana na floresta. Ele tem que escolher entre o benefício de satisfazer sua fome indo coletar nozes e o benefício de ficar descansando na cabana (que é sacrificado se ele decidir sair para coletar nozes). Se ele escolhe satisfazer sua fome, incorre numa perda de repouso. Essa perda do benefício do descanso (o sacrifício) é o custo de oportunidade da decisão de satisfazer a fome. A ação de sair é desencadeada sempre que há uma diferença entre o benefício de satisfazer a fome e o custo de oportunidade desta escolha (a perda ou sacrifício do descanso), ou seja, sempre que há um diferencial de benefício-sacrifício - um diferencial de utilidade. A ação de coletar nozes termina quando o benefício marginal decrescente (satisfação da fome) iguala o sacrifício marginal crescente (o esforço de ir coletar), momento em que o diferencial de utilidade passa a decrescer.

Heymann \& Bloom (1990, p. 10) observam que usualmente as decisões envolvem diversas alternativas e, neste caso, "o custo de oportunidade é determinado pelo mais valioso benefício sacrificado" de modo que:

"The [opportunity] cost of committing resources to any particular use is determined by the value of the resources in their best alternative use. By committing them to one use, all other possible uses are excluded. Some of these excluded uses are more valuable than others. It is the most valuable of them which is alone relevant in determining what has been sacrificed by committing the resources elsewhere-or in determining the 'cost' of committing them elsewhere". (Solomons, 1966, apud Heymann \& Blomm, id., p. 10-11)

Devido a essas características o custo de oportunidade não é uma abordagem "de custo", como "custo de produção", "custo de manutenção", etc., embora todo custo, como sacrifício de recurso, possa ser considerado custo de oportunidade. De fato, a abordagem dos custos de oportunidade tem por foco a valoração econômica, o preço como percepção de valor, a medida da receita (contra o custo de oportunidade) da alternativa escolhida - em suma, os trade-offs envolvidos nas escolhas que criam valor econômico.

Em economia internacional, os custos de oportunidade foram estudados desde o início do Séc. XIX como vantagem comparativa (Ricardo, 1937; Leontieff, 1985, p. 116 ss; Heymann \& Bloom, 1990, p. $27 \mathrm{ss}$ ), no conceito de vantagem competitiva das nações de Porter (1990b, p. 1ss) e, atualmente, na abordagem gerencial da cadeia internacional de valor (Hughes et al., 1998, p. 80-94). O custo de oportunidade do capital, estudado por muitos economistas, além de Ricardo e Leontieff, por exemplo, por Irving Fisher (1965) vem sendo divulgado pela abordagem do Economic Value Added (EVA®) que avalia o resultado das empresas após dedução do custo de oportunidade do capital investido (Chew, 1993; Al Ehrbar, 1998; Bown, 1999 e Monczka \& Morgan, 2000, entre outros).

A aplicação de custos de oportunidade na contabilidade financeira é bastante restrita - "opportunity costs are not recorded by accountants" - como notam Heymann \& Bloom (1990, p. 101). Do mesmo modo, observa Martins (2000, p. 33):

"O conceito de custo de oportunidade é um dos mais relevantes na economia e nas decisões... Mas sua não consideração na Contabilidade é (uma) mentira com a qual convivemos... A consideração do custo do capital próprio como sendo nulo é algo insustentável conceitualmente...”.

$\mathrm{Na}$ contabilidade gerencial, os custos de oportunidade do capital foram usados no RKW, no começo do Séc. XX, bem como por Slatter, Anthony e outros 
(Martins, 2000, p.33 ss) e, operacionalmente, são aplicados na determinação de preços de transferência em transações intra-firma, em geral entre unidades de negócios (Heymann \& Bloom, 1990, p. 107; Cats-Baril et al., 1998). Atualmente os custos de oportunidade são utilizados na Contabilidade Gerencial Estratégica (por ex. Ward,1993), bem como na Gestão Econômica.

Assim, a mensuração do resultado na Gestão Econômica é efetuada mediante a consideração da melhor alternativa, dentro de parâmetros do mercado. Por exemplo, nas transações que envolvem prazos de compra ou venda é considerada a incidência de taxas de juros de oportunidade pela meIhor alternativa de mercado, ou seja, pelas melhores taxas de aplicação ou captação que a empresa obteria no mercado ${ }^{8}$.

Mais genericamente, os parâmetros de valoração e de custo de oportunidade da Gestão Econômica são os preços correntes de mercado a vista, tanto de bens e serviços como taxas de juros. Pelos mesmos critérios econômicos, o valor do dinheiro no tempo é considerado mediante a aplicação dos conceitos de valor presente e moeda constante.

A ponderação de alternativas para a determinação do custo de oportunidade de uma decisão é efetuada no pressuposto de que sejam de risco equivalente. Por exemplo, a taxa de juros de oportunidade considerada na venda a prazo para o cliente $A$ ou $B$ será a mesma, desde que ambos tenham o mesmo risco de inadimplência, ou similar, dentro dos parâmetros da decisão (volume da venda, prazo do pagamento, etc). Do mesmo modo a comparação entre as taxas de juros de CDB oferecidas por dois bancos supõe que ambos tenham o mesmo "ranking" de risco de liquidez.

Esses critérios, aplicados ao conceito de ativo, possibilitam identificar e mensurar os ativos da empresa segundo as características dos benefícios deles decorrentes, como a seguir ${ }^{9}$ :

- as disponibilidades (caixa, bancos) valem o que expressam. Com efeito exprimem o valor monetário de liquidez corrente, dado pelo poder aquisitivo da moeda na data.
- os valores a receber são avaliados pelo seu valor presente, considerando a taxa de juros de captação da empresa no mercado e a probabilidade de recebimento. A taxa de captação é o custo de oportunidade expresso pela alternativa de a empresa captar recursos no mercado para financiar os recebíveis.

- os estoques valem o seu preço de mercado, segundo a fase de processamento em que se encontram. O preço de mercado é dado pelo menor preço corrente de venda do produto ou seu equivalente.

- as máquinas, os equipamentos produtivos e outros recursos, cuja utilização ocorre de maneira gradual ao longo do tempo, são mensurados pelo valor de mercado de seus serviços futuros, ajustado a valor presente, considerando a taxa de juros e a probabilidade de realização desses serviços. A oportunidade é a alternativa de obtenção dos mesmos serviços, por exemplo, mediante aluguel de um equipamento semelhante.

A importância da utilização de critérios econômicos na gestão empresarial, apesar das dificuldades de se medir aspectos incertos e subjetivos, já vem sendo considerada em algumas práticas da própria contabilidade societária. Assim, alguns ativos tradicionalmente mensurados pelo custo, hoje são contabilizados pelo fair value, ou seu valor de mercado, conforme o SFAS no 115 prescreve para os investimentos em títulos (debt and equity securities). Tratamento similar se observa para os derivativos, incluídos nos balanços a partir de 15/06/99, conforme o SFAS 133. Transparece, assim, uma tendência consistente na contabilidade americana para a contabilização pelo critério mark to market.

Com efeito, abordando os critérios de mensuração dos ativos, o AAA (American Accounting Association) já definia em 1957: "conceitualmente, a medida de valor de um ativo é a soma dos preços futuros de mercado dos fluxos de serviços a serem obtidos, descontados pela probabilidade de ocorrência e pelo fator juro, a seus valores atuais".

\footnotetext{
${ }^{8}$ Sobre os custos de oportunidade dos recursos financeiros e funções da área financeira, ver também Catelli et al.(1999).

${ }^{9}$ A esse respeito, ver Reis (1998, p. 691).
} 
Do mesmo modo, Bodenhorn (1961, p.585-6) preconiza que o contador deve aplicar o fluxo de caixa descontado na contabilização de ativos fixos,

“(...) reconhecendo ganhos e perdas de capital tão logo a administração reconheça que eles ocorreram. O contador pode objetar que isso é uma coisa excessivamente difícil de fazer (altamente subjetiva), uma vez que isso envolve uma estimativa contínua dos retornos futuros, que serão obtidos em cada projeto. Eu posso arguir somente que é o negócio da administração fazer tais estimativas, e tais estimativas são também continuamente feitas pelos investidores. (...) $\mathrm{O}$ objetivo do contador de um valor estável para os ativos da firma é na melhor das hipóteses uma miragem. O fato é que o valor da firma, e o valor dos ativos da firma, flutuam constantemente através do tempo, assim que os lucros futuros pareçam ser maiores ou menores. Um procedimento contábil que ignora esse fato óbvio é simplesmente um exercício contábil que não teria interesse para o homem de negócios." ${ }^{\text {10 }}$

Dessa forma, a consideração de qualquer ativo na Gestão Econômica inclui, no cálculo do seu valor presente, o risco, como probabilidade de ocorrência do valor esperado. Por isso, a mensuração do valor de um ativo, mediante o seu custo de oportunidade, inclui a consideração da probabilidade de ocorrência, como risco envolvido em cada alternativa de decisão. Por outro lado a taxa de juros de mercado para a empresa, como custo de oportunidade dos recursos financeiros envolvidos na decisão, inclui tanto o valor do dinheiro no tempo como o risco atribuído pelo mercado à empresa.

\section{O Enfoque na Gestão de Negócios}

A Gestão Econômica integra, em sua visão sistêmica, a adoção de critérios econômicos na mensuração das atividades da empresa e o enfoque de negócios como parâmetro de decisão para os seus gestores, na busca do resultado econômico de suas áreas de responsabilidade, consideradas centros de resultado, que objetivam o resultado otimizado do todo. Nessa abordagem, os gestores, em todas as suas atividades, têm em vista, não apenas a diminuição de custos, mas a geração de benefícios superiores aos custos incorridos, como sua contribuição para o resultado da organização.

Pela concepção de área de responsabilidade, o gestor atua como "dono do negócio" ou seja, como elemento pró-ativo dotado de empowerment para criar valor na sua área, contribuindo para o valor global da organização. É o que Peter Drucker, em 1990, preconiza para a empresa de 1999: "a transformação de gerentes funcionais em gerentes de negócios, cada um com um papel específico, mas todos membros da mesma produção e do mesmo elenco (1992, p. 208).

Nessa concepção os gestores partem do ponto de vista de que o resultado global da empresa é produzido a partir das atividades realizadas nas suas respectivas áreas de responsabilidade. Assim, atuando sistemicamente, o gestor de área não visa simplesmente a maximização do seu desempenho dentro de sua área, mas sim a sua melhor contribuição para o resultado do todo. Assim, o resultado objetivado pelas áreas de responsabilidade é o resultado otimizado e não simplesmente maximizado.

As áreas de responsabilidade consideradas como centros de negócios, contribuem para a geração do resultado, em todos os seus níveis de decisão, desde as mais gerais até as mais pontuais, abrangendo todas as suas atividades, eventos e transações.

Por outro lado, para efeito de decisão, muitas das transações efetuadas pelo gestor envolvem as mesmas variáveis e provocam impactos econômicos semelhantes no resultado e patrimônio da empresa. Assim, essas transações são classificadas em eventos, conforme sua relevância dentro das características de cada empresa. Como diz Pereira (1998, p. 14) "um evento econômico refere-se a um conjunto de transações de mesma natureza, cujo impacto econômico pode ser mensurado da mesma forma (...). A transação consiste (...) no menor nível em que pode ser identificado o resultado econômico".

${ }^{10}$ Ver também Guerreiro (1989, p.195-6). 
Pode-se, assim, dizer que só a contabilidade que atinge a geração do resultado nesse nível mínimo de detalhamento, no qual são efetivamente gerados todos os resultados da empresa, ou seja, só uma contabilidade baseada em eventos é efetivamente gerencial.

Sendo assim, a Gestão Econômica, a partir da estrutura lógica subjacente à tomada de decisão em cada evento, constrói um modelo de decisão ${ }^{11}$ genérico que, pelo fato de aplicar-se a cada evento, aplicase também a todas as decisões da empresa. Tal modelo exprime as variáveis que impactam o resultado econômico de cada decisão, permitindo ao gestor a escolha da melhor alternativa, conforme segue.

\section{Quadro 2: Modelo de Decisão na Gestão Econômica}

\begin{tabular}{|l|l|l|l|}
\hline & ALTERNATIVA A & ALTERNATIVA B & ALTERNATIVA C \\
\hline Receitas Operacionais & & & \\
(-) Custos/Despesas Operacionais & & \\
(=) MARGEM DE CONTRIBUIÇÃO OPERACIONAL & & & \\
\hline Receitas Financeiras & & & \\
(-) Despesas Financeiras & & & \\
(=) MARGEM DE CONTRIBUIÇÃO FINANCEIRA & & & \\
\hline (-) Custos/Despesas Fixas & & & \\
\hline (=) RESULTADO ECONÔMICO & & \\
\hline
\end{tabular}

A configuração do modelo de decisão básico, ao expressar uma síntese estrutural lógica de todas as decisões, possibilita o raciocínio congruente dos gestores na busca do resultado global e a utilização de critérios uniformes na avaliação dos diversos impactos das suas decisões.

Os impactos operacional, financeiro, econômico e patrimonial das decisões dos gestores são representados no quadro 3, a qual mostra como cada evento reproduz as diversas dimensões do fluxo de negócios que ocorre no todo do sistema em empresa.

A dimensão operacional enfoca o impacto da decisão no ciclo produtivo, pelo qual recursos são processados, transformando-se em produtos. A gestão operacional preocupa-se com a qualidade e quantidade de recursos consumidos e bens e serviços gerados, com os prazos de produção e entrega e, em geral, com a eficiência e produtividade.
A dimensão financeira envolve a utilização de recursos financeiros e a administração dos prazos de pagamento e recebimento em função dos juros e outros custos de capital, que caracterizam a gestão do impacto financeiro das decisões.

A dimensão econômica exprime a integração do fluxo produtivo e do fluxo financeiro, no fluxo de custos e receitas, que gera o resultado econômico (gestão econômica) da decisão.

A dimensão patrimonial parte do princípio de que o resultado econômico corresponde a uma diferença no patrimônio da empresa ocorrida em consequência da respectiva decisão. A gestão patrimonial preocupa-se com os impactos da decisão na estrutura dos seus ativos (por exemplo, diminuição do estoque e aumento do caixa ou diminuição do caixa e aumento dos ativos fixos) e passivos (por exemplo, aumento dos ativos fixos e do exigível a longo prazo).

${ }^{11}$ Sobre o tratamento dos modelos de decisão na Gestão Econômica, ver Almeida (1996) e Santos \& Ponte (1998). 


\section{Quadro 3: Dimensões Operacional, Econômica, Financeira e Patrimonial das Decisões}

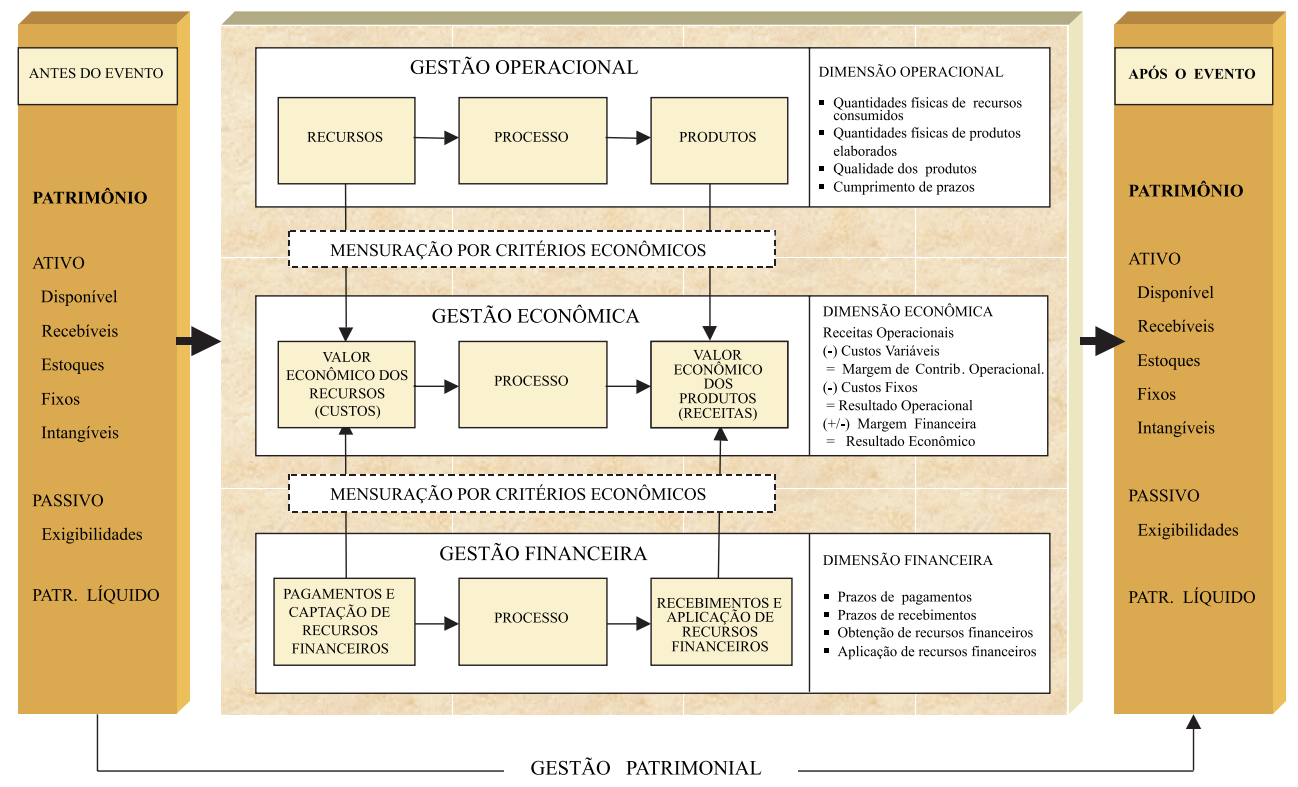

Fonte: Adaptado de Catelli et al.(1997) e Pereira (1999).

O enfoque de negócios pode ser sintetizado numa visão integrada do resultado como parâmetro de todas as decisões dos gestores, das transações à empresa como um todo. Assim, conforme a expressão do quadro 4 , os resultados das transações $(T)$, classificadas e acumuladas em eventos $(E)$, integram os resultados das atividades $(A)$ e, estes, os resultados das áreas de responsabilidade ou divisões (D) cujo somatório compõe o resultado da empresa (EM):

\section{Quadro 4: Processo de Acumulação de Resultados}

$\Sigma \mathrm{T}=\mathrm{E} \Rightarrow \Sigma \mathrm{E}=\mathrm{A} \Rightarrow \Sigma \mathrm{A}=\mathrm{D} \Rightarrow \Sigma \mathrm{D}=\mathrm{EM}$ Onde:

$\mathrm{T}=$ Transação

$\mathrm{E}=$ Evento

$A=$ Atividade

$\mathrm{D}=$ Divisão

$\mathrm{EM}=$ Empresa

Fonte: Parisi (1995, p.53).

\section{GESTÃO ECONÔMICA DE INVESTIMENTOS EM ATIVOS FIXOS}

Mais do que outros elementos do sistema empresa, os ativos fixos, na sua identificação e mensuração, manifestam-se em interação com os demais elementos do sistema empresa. Por isso, o tratamento dos ativos fixos realça os aspectos integrativos da visão sistêmica e gerencial da Gestão Econômica.

Partindo-se do conceito genérico de ativo como um gerador potencial de benefícios futuros, a identificação de ativos fixos, bem como sua distinção dos demais ativos é obtida considerando-se a diversidade dos impactos desses benefícios na consecução dos objetivos da organização. Assim, na visão sistêmica da empresa esses impactos podem ser visualizados sob os enfoques da gestão operacional, financeira, econômica e patrimonial, na medida em que contribuem para a eficácia da organização, na obtenção dos resultados presentes e futuros da empresa. 


\subsection{Gestão Operacional, Financeira, Econômica e Patrimonial dos Ativos Fixos}

Sob o enfoque operacional, os ativos fixos são utilizados de modo gradual, durante anos, no ciclo produtivo de transformação, enquanto que os ativos correntes são consumidos rapidamente, de modo integral. O gerenciamento operacional deve levar em conta que os ativos fixos, por sua natureza, são determinantes de muitos outros ativos e atividades operacionais, configurando o perfil da mão-de-obra, as características do processo de produção, por exemplo, se em grandes ou pequenos lotes, os tipos de matéria-prima e outros insumos, o perfil da estocagem, as relações com fornecedores, as especificações e a qualidade dos produtos, a estrutura de custos de produção, o volume produzido, os prazos de entrega, etc.

A contribuição do ativo fixo para o resultado (margem) operacional obedece a variáveis de eficiência, flexibilidade, qualidade, etc., determinadas pela sua interação com os demais subsistemas da empresa que atuam no ciclo produtivo. ${ }^{12}$ Essa margem é obtida reduzindo-se a valor presente os benefícios a serem gerados pelo ativo fixo, líquidos dos custos de aquisição e de manutenção.

Esses benefícios não podem ser confundidos com os produtos da empresa, uma vez que o processo de produção, além dos ativos fixos nele utilizados, exige a interação de outros fatores e elementos da organização. Assim, os benefícios gerados pelos ativos fixos são os serviços específicos que estes ativos desempenham dentro da operação da empresa, por exemplo, no caso de máquinas, dados pelo número de horas-máquina utilizados.

A manutenção é considerada um recurso sacrificado, diretamente identificado ao ativo e a ele inerente porque é condição de continuidade do ativo na sua identidade funcional e operacional, motivo pelo qual é deduzida dos benefícios futuros para que sejam obtidos os benefícios líquidos. Do ponto de vista do capital investido, a manutenção constitui um desembolso adicional de capital, necessário para assegurar o valor do investimento, ou seja, sua capacidade sustentada de gerar fluxos de benefícios.

Sob o enfoque financeiro, os ativos fixos constituem investimentos de capital, geralmente de somas elevadas, de retorno incerto e a longo prazo, devendo esse risco ser considerado para efeito de remuneração do capital, bem como para a gestão da liquidez da empresa. A consideração da taxa de risco é feita, por exemplo, mediante a aplicação de probabilidades na projeção dos resultados.

Os mesmos critérios se aplicam aos ativos correntes, diferenciando-se, porém, pelo horizonte de curto prazo, que reduz a incerteza, pela utilização de um volume normalmente menor de recursos financeiros, bem como maior liquidez em relação aos ativos fixos. A margem de contribuição financeira de um ativo fixo ocorre quando o mesmo é financiado a taxas de juros inferiores às taxas de aplicação da empresa no mercado ${ }^{13}$.

As decisões de investimento são frequentemente acompanhadas por decisões de financiamentos, tais como, leasing, project finance etc., que são tratadas por eventos econômicos específicos, expressos nas margens financeiras, que podem ser consolidadas no resultado global do investimento.

Do ponto de vista econômico, o ativo fixo deve produzir um fluxo de benefícios futuros superiores ao fluxo de todos os custos, operacionais e financeiros, por ele ocasionados. O resultado econômico do investimento que constitui o ativo fixo sintetiza, portanto, na forma de custos e receitas, todos os eventos presentes e futuros originados pelo ativo. $\mathrm{O}$ investimento em ativo fixo é, portanto, um evento que, como todos os outros eventos da empresa, deve gerar um resultado positivo, como tal, contribuindo para o resultado do todo.

Ao contrário dos eventos que impactam o resultado de curto prazo, como no caso de transações com ativos correntes, o investimento em ativos fixos impacta o resultado durante os vários anos da vida útil desse ativo. Esses impactos sucessivos constituem os fluxos de custos e receitas que ocorrerão no futuro, mas que podem ser projetados desde hoje, constituindo a base da decisão do investimento. Essa projeção leva

\footnotetext{
${ }^{12}$ Ver por exemplo, Cortés (1997).

${ }^{13}$ Do mesmo modo, já visto anteriormente, que se pode obter uma margem financeira numa compra a prazo a custos financeiros abaixo da taxa de oportunidade de aplicação da empresa.
} 
em conta variáveis econômicas como inflação, taxa de juros, variações na demanda, competitividade da empresa, preços de mercado, custos, riscos e incerteza, etc. Todos esses fatores são combinados, projetados e mensurados, formando os fluxos acima referidos de custos e benefícios operacionais e financeiros. Computam-se, separadamente, reduzindo-se a valor presente mediante aplicação de taxas de desconto, os custos e benefícios operacionais projetados - que constituem a margem operacional -e os custos e benefícios financeiros projetados - que constituem a margem financeira. $O$ valor presente líquido obtido constitui o resultado do investimento.

Sob o aspecto patrimonial, o ativo fixo é considerado um estoque gerador de riqueza (uma árvore que dá frutos, na imagem de Solomons, apud Guerreiro,1992, p.6), provocando variações no valor do patrimônio da empresa através do tempo. A gestão patrimonial considera ainda outras interações patrimoniais com outros ativos (por exemplo, seu impacto no caixa, caso a vista,) ou com passivos (seu impacto na estrutura de capitais, caso a prazo).

No momento inicial do investimento, uma vez decidido e contratado, o valor patrimonial do ativo é dado pelo fluxo dos serviços futuros, descontados pela probabilidade de ocorrência e pela taxa de juros; a variação patrimonial é dada pelo valor presente dos serviços futuros do ativo, líquido do valor de aquisição.

Num determinado momento da vida útil do ativo fixo, o seu valor patrimonial é dado pelos benefícios futuros da sua vida remanescente, descontados pelos juros e probabilidade de ocorrência. $\mathrm{O}$ valor da variação patrimonial entre este momento e o momento anterior é a diferença entre o valor presente do fluxo dos benefícios remanescentes, líquidos dos seus custos, em relação aos dois momentos, ou seja, é o consumo de parte dos serviços do ativo, que constitui a sua depreciação.

No fim da vida útil do ativo para a empresa, o seu valor é dado pela receita líquida de venda no estado em que se encontra. A variação patrimonial é a diferença entre a receita líquida de venda e o valor presente líquido dos serviços remanescentes do bem para a empresa.

\subsection{O Gerenciamento Econômico do Investimento}

Na aplicação dos critérios acima ao processo de gestão econômica dos investimentos em ativos fixos, podem-se distinguir quatro momentos relevantes a serem analisados: a decisão de investir (momento $t_{0}$ ), a efetivação do investimento, dada, por exemplo, pela aquisição, construção, montagem ou preparação do ativo fixo (momento $t_{1}$ ), a utilização dos benefícios do ativo fixo (momentos $t_{2} a t_{n}$ ) e a decisão de alienação ou abandono do investimento (momento $\mathrm{t}_{\mathrm{n}+1}$ ).

No momento $t_{0}$, o gestor coloca-se diante da decisão de investir ou não para ter acesso aos benefícios e serviços de um determinado ativo fixo. Com efeito, supõe-se, como ocorre frequentemente, que os mesmos serviços do ativo fixo podem ser obtidos mediante outras alternativas possíveis como, por exemplo, o aluguel do equipamento. Esta decisão pode ser denominada "decisão de Investir" no ativo fixo. Caso não se opte pelo aluguel, mas pela compra do equipamento, esta pode ser realizada com recursos próprios (decisão de "Compra à Vista") ou financiada (decisão de "Compra a Prazo").

Trata-se, portanto, de três eventos distintos (decisão de investir, decisão de adquirir uma determinada máquina e a decisão de financiar a aquisição da máquina). Esses eventos são específicos, na medida em que apresentam impactos distintos no patrimônio, sendo seus resultados atribuídos às respectivas áreas de responsabilidade, segundo o modelo de gestão da empresa.

Assim, supondo-se um modelo de gestão de empresa com característica descentralizadora, a decisão de investir, em benefício de uma determinada operação produtiva, cabe normalmente ao gestor da área de responsabilidade Produção, o qual pode, alternativamente, alugar o equipamento. As decisões envolvidas na compra da máquina são do gestor de Compras, ao qual compete analisar os diversos preços e condições dos fornecedores, sendo avaliado pelo resultado obtido nessa decisão. As condições financeiras do investimento, conforme o modelo de gestão da empresa, estão normalmente a cargo da 
área financeira, apta a melhor negociar linhas de financiamento, prazos e taxas, produzindo uma contribuição financeira para o resultado econômico do investimento.

Esses parâmetros, aplicados ao modelo genérico de decisão da Gestão Econômica representado no quadro 2, formam o Modelo da Decisão de Investimento, conforme quadro 10.

No exemplo, supõe-se que os gestores da empresa já decidiram que, para fabricar ou modificar um determinado produto, necessitam utilizar os serviços de um ativo fixo, por exemplo, um torno mecânico, do qual a empresa não dispõe. Supõe-se que haja no mercado um torno adequado, que pode ser alugado ao valor de $\$ 2,00$ por hora de serviço, ou ser adquirido ao preço a vista de mercado $\$ 60.000,00$; no

As taxas de juros de mercado previstas para a empresa, por período, são de $10 \%$ na aplicação e $12 \%$ na captação e a inflação prevista é zero. Por razões de simplicidade didática, o exemplo não considera as probabilidades de ocorrência dos eventos projetados. A empresa pode obter um financiamento especial para a máquina em uma agência de fomento pelo custo de $9 \%$ por período, pagável em 5 prestações iguais no final de cada período, segundo o Sistema Francês de amortização ou Tabela Price.

Conhecidos os valores iniciais acima, a primeira medida do decisor é obter o valor presente do fluxo de serviços futuros do ativo, o que é feito mediante a aplicação de uma taxa de desconto de oportunidade, equivalente aos juros de captação do mercado, neste caso, $12 \%$. Entende-se, com isso, que a área entanto, o gestor de compras, prevê que, após negociação, o ativo pode ser adquirido por $\$ 58.000,00$. Seu custo de manutenção será de $\$ 1,00$ a hora e o torno será utilizado por 5 períodos, com o volume de horas de serviço e de manutenção, conforme segue.

Quadro 5: Número de Horas de Utilização e de Manutenção

\begin{tabular}{|ccc|}
\hline Período & Horas-Máquina & Horas-Manutenção \\
\hline 1 & 10.000 & 500 \\
2 & 10.000 & 600 \\
3 & 10.000 & 600 \\
4 & 10.000 & 800 \\
5 & 10.000 & 800 \\
\hline
\end{tabular}

de responsabilidade que decide o investimento inclui na sua decisão a remuneração do capital à mesma taxa que a empresa o tomaria no mercado ${ }^{14}$.

A seguir é calculado o valor presente dos custos de manutenção do ativo fixo pelo seu período previsto de uso na empresa, aplicando-se ao fluxo desses desembolsos futuros a taxa financeira de oportunidade prevista para aplicação, no caso, 10\%. Entende-se que os custos de manutenção são provisões para gastos futuros, cuja oportunidade, como se verifica para todos os passivos, decorre da não utilização imediata do dinheiro, o qual poderia ser aplicado no mercado.

Do valor presente dos serviços futuros do torno, é deduzido o valor presente dos seus custos futuros de manutenção, obtendo-se o valor presente líquido dos serviços, ou seja, dos benefícios gerados pelo ativo, conforme quadro 6.

\section{Quadro 6: Apuração do Valor Presente dos Serviços do Ativo e sua Manutenção}

\begin{tabular}{|c|c|c|c|c|c|}
\hline \multirow[b]{2}{*}{ Período } & \multicolumn{2}{|c|}{ Valor dos Serviços } & \multicolumn{2}{|c|}{ Valor da Manutenção } & \multirow{2}{*}{$\begin{array}{c}\text { Valor Presente Líquido } \\
\text { dos Serviços }\end{array}$} \\
\hline & Futuro & Presente & Futuro & Presente & \\
\hline 1 & $20.000,00$ & $17.857,14$ & 500,00 & 454,55 & $17.402,59$ \\
\hline 2 & $20.000,00$ & $15.943,88$ & 600,00 & 495,87 & $15.448,01$ \\
\hline 3 & $20.000,00$ & $14.235,61$ & 600,00 & 450,79 & $13.784,82$ \\
\hline 4 & $20.000,00$ & $12.710,36$ & 800,00 & 546,41 & $12.163,95$ \\
\hline 5 & $20.000,00$ & $11.348,54$ & 800,00 & 496,74 & $10.851,80$ \\
\hline 5 & $5.000,00$ & $2.837,13$ & - & - & $2.837,13$ \\
\hline Total & $105.000,00$ & $74.932,66$ & $3.300,00$ & $2.444,36$ & $72.488,30$ \\
\hline
\end{tabular}

${ }^{14}$ Não cabe aqui detalhar que tipo de linha de financiamento deve ser considerada como parâmetro de mercado para os custos de oportunidade de investimento, uma vez que tal depende das características da empresa e do investimento e da configuração e circunstâncias, às vezes voláteis, de cada mercado financeiro. Parece claro, porém, que devem ser usadas taxas distintas das empregadas nos financiamentos de curto prazo. 
O valor presente dos serviços futuros proporcionados pelo ativo, líquido dos seus custos futuros de manutenção, também a valor presente, constitui o valor do ativo para a empresa, numa aplicação direta do conceito de ativo definido anteriormente.

$O$ valor presente líquido do investimento nesse ativo é dado pelo valor do ativo para a empresa, como acima apurado (\$72.488), deduzido do seu valor de mercado, no caso, $\$ 60.000,00$, perfazendo, o total de $\$ 12.488$. Este valor constitui o resultado operacional da decisão de investir no torno, constituindo o motivo último da decisão do gestor da área de Produção de fazer o investimento, adquirindo $o$ ativo.

Ao efetivar a compra do torno, conforme o modelo de decisão descrito no quadro 10, o gestor da área de responsabilidade Compras procura negociar um preço mais vantajoso que o vigente no mercado, a fim de obter nesta transação uma margem de contribuição para o resultado do investimento e da empresa. Esta margem é obtida, considerando-se o valor de compra do ativo ao preço vigente de mercado, como custo de oportunidade, pelo qual o torno será transferido por Compras à Produção $(\$ 60.000,00)$, e que constitui a receita de oportunidade de Compras. Esse valor é deduzido do custo efetivo da máquina $(\$ 58.000,00)$, resultando na margem de $\$ 2.000,00$ na compra da mesma.

Assim, conforme o mesmo quadro 10, a margem operacional do investimento é dada pela margem operacional da aquisição dos serviços do ativo, de responsabilidade da área de Produção (\$ 12.488), somada à margem operacional da aquisi- ção do torno, de $\$ 2.000,00$, obtida pela área de Compras.

A Área Financeira, por sua vez, opta por financiar o investimento, utilizando uma linha de fomento de mercado, a taxas favoráveis $(9 \%)$ em relação à taxa de aplicação de 10\%, considerada como parâmetro para efeitos de custo de oportunidade financeira. Neste caso, o parâmetro é a taxa de aplicação, e não a de captação. Com efeito, entende-se que, ao optar por financiar o investimento, a área financeira deixa de utilizar recursos de capital dos acionistas, que podem aplicá-lo no mercado financeiro. É claro que, se a empresa não conseguisse uma taxa de financiamento inferior à taxa de remuneração do capital próprio, que é a taxa de aplicação, ela não utilizaria o financiamento, mas sim o aporte de capital. A razão de os recursos de capital próprio serem remunerados pela taxa de aplicação é que o acionista tem como custo de oportunidade a aplicação de seus recursos no mercado financeiro. Ao aplicar seus recursos na empresa, embora com maior risco do que no mercado financeiro, o acionista aceita essa taxa como mínima, uma vez que espera da empresa resultados econômicos adicionais aos desta aplicação.

Desse modo, conforme quadros 7, 8 e 9, a margem financeira foi obtida tomando-se como receita financeira de oportunidade o valor presente dos juros de oportunidade do financiamento à taxa de aplicação de $10 \%$, perfazendo o total de $\$ 14.817$. Desse valor se deduziu o valor presente dos juros exigíveis, negociados para o financiamento, de \$13.268, chagando-se à margem de contribuição financeira de $\$ 1.549$.

\section{Quadro 7: Juros Incorridos no Financiamento}

\begin{tabular}{|c|c|c|c|c|}
\hline Período & Saldo Devedor & Amortização & Juros 9\% \\
\hline 0 & $58.000,00$ & $9.691,36$ & $5.220,00$ \\
\hline 1 & $58.000,00$ & $10.563,59$ & $4.347,78$ \\
\hline 2 & $48.308,64$ & $11.514,31$ & $3.397,05$ \\
\hline 3 & $37.745,05$ & $12.550,60$ & $14.911,36$ \\
\hline 4 & $26.230,74$ & $13.680,15$ & $1,36,77$ \\
\hline 5 & $13.680,15$ & $\mathbf{5 8 . 0 0 0 , 0 0}$ & $1.231,21$ \\
\hline Total & $\mathbf{0 , 0 0}$ & $\mathbf{1 6 . 5 5 6 , 8 1}$ & $14.911,36$ \\
\hline
\end{tabular}




\section{Quadro 8: Juros de Oportunidade do Financiamento}

\begin{tabular}{|c|c|c|c|c|}
\hline $\begin{array}{c}\text { Período } \\
0\end{array}$ & Saldo Devedor & Amortização & Juros 10\% & Prestação \\
\hline 1 & $58.000,00$ & & & $15.300,25$ \\
\hline 2 & $58.000,00$ & $9.500,25$ & $5.800,00$ & $15.300,25$ \\
\hline 3 & $48.499,75$ & $10.450,28$ & $3.849,97$ & $15.300,25$ \\
\hline 4 & $38.049,47$ & $11.495,31$ & $2.604,95$ & $15.300,25$ \\
\hline 5 & $26.554,16$ & $12.644,84$ & $\underline{1.390,93}$ & $\underline{15.300,25}$ \\
\hline Total & $\underline{13.909,32}$ & $\underline{13.909,32}$ & $\mathbf{1 8 . 5 0 1 , 2 7}$ & $\mathbf{7 6 . 5 0 1 , 2 7}$ \\
\hline
\end{tabular}

Quadro 9: Cálculo da Margem Financeira: Custos (-) Receitas Financeiras de Oportunidade

\begin{tabular}{|c|c|c|c|c|c|}
\hline \multirow[b]{2}{*}{ Período } & \multicolumn{2}{|c|}{ Custo $9 \%$} & \multicolumn{2}{|c|}{ Custo Oportunidade $10 \%$} & \multirow[b]{2}{*}{$\begin{array}{r}\text { Margem } \\
\text { Financeira }\end{array}$} \\
\hline & $\begin{array}{r}\text { Valor no final } \\
\text { do período }\end{array}$ & $\begin{array}{l}\text { Valor } \\
\text { Presente }\end{array}$ & $\begin{array}{r}\text { Valor no final } \\
\text { do período }\end{array}$ & $\begin{array}{l}\text { Valor } \\
\text { Presente }\end{array}$ & \\
\hline 1 & $5.220,00$ & $4.745,45$ & $5.800,00$ & $5.272,73$ & 527,27 \\
\hline 2 & $4.347,78$ & $3.593,20$ & $4.849,97$ & $4.008,24$ & 415,04 \\
\hline 3 & $3.397,05$ & $2.552,26$ & $3.804,95$ & $2.858,71$ & 306,46 \\
\hline 4 & $2.360,77$ & $1.612,44$ & $2.655,42$ & $1.813,68$ & 201,25 \\
\hline 5 & $1.231,21$ & 764,49 & $1.390,93$ & 863,66 & 99,17 \\
\hline Total & $16.556,81$ & $13.267,84$ & $18.501,27$ & $14.817,03$ & $1.549,19$ \\
\hline
\end{tabular}

O resultado econômico do investimento (\$16.037), conforme quadro 10 , é obtido pela soma da margem operacional dos serviços do ativo (torno) $(\$ 12.488)$ com a margem operacional de aquisição do torno (\$2.000), que formam a margem de contribuição operacional do investimento (\$14.488), com a margem de contribuição financeira do investimento (\$ 1.549).

\section{Quadro 10: Modelo da Decisão de Investimento}

\begin{tabular}{|lr|}
\hline Receita Operacional dos Serviços & 74.933 \\
(-) Custos Operacionais dos Serviços & \\
Custo de Aquisição dos Serviços & $(60.000)$ \\
Custo de Manutenção dos Serviços & $(2.444)$ \\
(=) Margem Operacional dos Serviços & 12.488 \\
\hline Receita Operacional da Compra do Torno & 60.000 \\
(-) Custos de Aquisição & $(58.000)$ \\
(=) Margem Operacional de Aquisição & 2.000 \\
\hline (=) MARGEM DE CONTRIBUIÇÃO OPERACIONAL & $\mathbf{1 4 . 4 8 8}$ \\
\hline Receitas Financeiras & 14.817 \\
(-) Despesas Financeiras & $(13.268)$ \\
\hline (=) MARGEM DE CONTRIBUIÇÃO FINANCEIRA & $\mathbf{1 . 5 4 9}$ \\
\hline (=) RESULTADO ECONÔMICO & $\mathbf{1 6 . 0 3 7}$ \\
\hline
\end{tabular}

A decisão de investimento tomada em $\mathrm{t}_{0}$ projetou todo o ciclo de vida do ativo na empresa, até a sua alienação. Todos os valores considerados em to são valores projetados e planejados, portanto, não necessariamente idênticos aos valores que ocorrerão na implementação real do investimento e durante a sua vida útil real.

Assim, o resultado econômico do investimento em $\mathrm{t}_{0}$, conforme acima, é um resultado esperado, que deverá ser continuamente monitorado e comparado ao resultado realmente obtido na implantação e ciclo de vida efetiva do ativo.

Durante o ciclo de vida ( de $_{2}$ a $t_{n}$ ), os serviços do ativo, do torno no caso, vão sendo consumidos em benefício do ciclo de produção de outros bens e serviços que contribuem para o resultado da empresa. Ocorrem assim, a depreciação e a manutenção, da qual já se tratou anteriormente. Entretanto, pode o monitoramento mostrar a conveniência de se reinvestir no ativo, prolongando sua vida útil, ou incrementando seu potencial de benefícios futuros.

O conceito econômico de depreciação foi aceito em 1957 pela $A A A$, que considera que o ativo 
representa um estoque de serviços que pode ser liberado durante a vida do ativo; o declínio nesse potencial de serviço constitui a depreciação, a qual pode ocorrer por deterioração física, consumo pelo uso ou perda do valor econômico por obsolescência ou por mudanças na demanda (Hendriksen \& van Breda, 1992, p.529; ludícibus, 1997; e Ramos, 1968).

Segundo Reis (1997, passim), há que se distinguir entre a perda de valor como fenômeno de natureza tempo-conjuntural, que foge ao controle da gestão (como obsolescência, mudança na demanda, etc.), da depreciação propriamente dita, que consiste no consumo do ativo, ocasionado pelas suas horas de uso na produção de bens e serviços, a cujo valor agregado se incorpora. Segundo esse autor, a depreciação não é a perda de valor do bem, embora ela ocasione uma diminuição de valor, mas sim exclusivamente a realização do potencial dos benefícios do ativo.

O enfoque econômico da depreciação faz com que esta seja considerada, não um custo indireto, vinculado ao período e alocado a produtos e áreas de responsabilidade por meio de rateios, mas sim como um custo variável, por hora-máquina utilizada, diretamente identificado aos produtos gerados pelo ativo.

Esse conceito possibilita ainda que os custos de depreciação sejam somente identificados com atividades e áreas de responsabilidades que exerçam controle sobre os mesmos, de forma que os respectivos gestores sejam avaliados apenas pela gestão dos custos e benefícios que efetivamente controlam. Esse princípio da controlabilidade é fundamental no sistema de avaliação de desempenhos da Gestão Econômica, como ficou acima ressaltado na apuração das diversas margens de contribuição que compõem o resultado do investimento.

A decisão de desinvestir ou abandonar um ativo fixo (em $t_{n+1}$ ), que conserva um potencial futuro de serviços, decorre do fato de esses serviços não mais contribuírem para o resultado da empresa. Tal pode ocorrer por razões funcionais como reorganização do processo produtivo, mudança da linha ou especificações de produtos, introdução de novas tecnologias etc.
Do ponto de vista econômico, um parâmetro básico para o desinvestimento de um ativo durante a sua vida útil é que o total dos benefícios a serem gerados em sua vida remanescente seja inferior ao seu valor líquido de realização no mercado. Tal ocorre, necessariamente, quando o seu potencial específico de serviços se consumiu inteiramente, momento em que deixa de ter valor operacional, convertendo-se em sucata, ou quando o custo de manutenção previsto torna-se, num determinado momento real, superior ao valor esperado dos benefícios futuros.

O momento adequado para o desinvestimento é aquele em que o ativo, não servindo mais à empresa, mantém ainda um fluxo de benefícios futuros para o potencial comprador, de tal modo que possa alcançar um preço de venda, no mínimo, suficiente para cobrir os diversos custos, inclusive de oportunidade, incorridos no desinvestimento.

\section{CONCLUSÃO}

Mais do que outros temas contábeis, a mensuração dos ativos fixos traz à tona o problema da tensão entre objetividade e relevância, cuja busca originou e fez desenvolver até hoje a ciência contábil.

Se esta sempre esteve intimamente relacionada com a ciência e as realidades econômicas (Littleton \& Zimmerman, 1962, p.170, passim) o seu afastamento tem preocupado estudiosos e afetado a eficácia das empresas, a relevância das informações e o próprio rigor da objetividade científica almejada.

A Gestão Econômica considera sistemicamente a empresa, numa abordagem renovada dos critérios econômicos da mensuração contábil e numa visão gerencial, "de negócios", voltada para a otimização do resultado econômico das decisões dos gestores, nas transações, eventos, atividades e áreas de responsabilidade, na busca do resultado global da organização.

A inseparabilidade entre resultado e patrimônio reflete-se no conceito de ativo, em particular de ativo fixo, como elemento gerador de benefícios futuros, mensurados pelo valor presente do seu fluxo de caixa líquido, descontado as taxas de oportunidade de mercado. 
No exame dos investimentos em ativos fixos, a recuperação da objetividade e relevância no tratamento dos custos, evitando as arbitrariedades dos rateios, converte custos, tradicionalmente fixos de depreciação, em custos variáveis, por hora de utilização, perfeitamente identificados aos produtos, bem como aos eventos, atividades e áreas.

Possibilita-se, assim, a análise de desempenho a partir de parâmetros de fato controláveis pelos gestores. O reconhecimento e, com este, a própria consecução dos resultados sob a forma de margens de contribuição das decisões permite a otimização operacional, financeira, econômica e patrimonial do investimento, como evento gerador de riqueza.

O modelo de decisão de investimento permite o seu gerenciamento e acompanhamento de todo o seu ciclo de vida, estendendo a abrangência da mensuração contábil ao fluxo dos acontecimentos futuros que valoram, desde o momento da decisão inicial, os ativos e as empresas.

Assim, a contabilidade, dentro de sua origem e evolução até o presente de mudanças e competitividade, voltada para o futuro, pode afirmar: "What we cannot know about the future will not be known no matter how hard the prophets stare into their assorted crystals; but what can be known, and it is on the skeptic's own showing far from negligible, can be rationally used to carry us into the future with some understanding of what we are doing and of the resources on which we can draw to meet its risks and surprises, whatever they may prove to be, with intelligence and resolution" (Murphy, 1957, apud Littleton \& Zimmermnan, 1962, p.15).

\section{REFERÊNCIAS BIBLIOGRÁFICAS}

ALMEIDA, Lauro B. Estudo de um modelo conceitual de decisão, aplicado a eventos econômicos, sob a ótica da gestão econômica. Dissertação (Mestrado) FEA/USP. São Paulo, 1996.

BARROS, Elizabeth F. \& NOSSA, Valcemiro. Decisões financeiras e impactos tempo-conjunturais. Caderno de Estudos-FIPECAFI, v. 10, № 18, páginas 51-66, maio/agosto, 1998.

BEUREN, Ilse M. Modelo de mensuração do resultado de eventos econômicos empresariais: um enfoque de sistema de informação de gestão econômica. Tese (Doutoramento) - FEA/USP. São Paulo, 1994.

BODENHORN, Diran. An economist looks at industrial accounting and depreciation. The Accountig Review, vol XXXVI, no 4, p. 582-588, outubro, 1961.

CATELLI, Armando (Org.) CONTROLADORIA: Uma abordagem de Gestão Econômica - GECON. São Paulo: Atlas, 1999.

CATELLI, Armando et al. Sistema de Gestão Econômica - GECON: um instrumento para mensuração, otimização e avaliação de resultados e desempenhos.
Anais do V Congresso Internacional de Costos. Acapulco, 1997.

CATELLI, Armando \& GUERREIRO, Reinaldo. Uma análise crítica do sistema ABC - Activity Based Costing. In: XVII Jornada de Contabilidade, Economia e Administração do Cone Sul. Boletin IOB. Temática contábil e balanços. no 39/94. p. 327-22.

CATELLI, Armando et al. Avaliação de resultados e desempenhos em Instituições Financeiras: enfoque de gestão econômica (Gecon). Revista de Contabilidade do CRC-SP, ano II, № 6, Novembro de 1998.

Gestão econômica da atividade financeira na empresa. In: Anais do VI Congresso Brasileiro de Custos.1999.

CATELLI, Armando \& SANTOS, Edilene S. Measuring the value chain by opportunity costs. In: $V$ International Seminar on Manufacturing Accounting Research. EIASM, Pisa, Italy, June, 2001.

CHEW, Donald H. Jr. The new corporate finance. New York: McGraw-Hill,1993. 
CORTÉS, Angélica A. P. Estudo exploratório de um sistema de informação de investimento para ativo fixo: uma abordagem contábil. Dissertação (Mestrado) - FEA/ USP. São Paulo, 1997.

DRUCKER, Peter F. Administrando para o futuro. Tradução de Nivaldo Montingelli jr. São Paulo: Pioneira, 1992.

GUERREIRO, Reinaldo. Modelo conceitual de sistema de informação de gestão econômica: uma contribuição à teoria da comunicação da contabilidade. Tese (Doutorado) - FEA/USP. São Paulo, 1989.

A meta da empresa: seu alcance sem mistérios. São Paulo: Atlas, 1996.

A teoria das restrições e o sistema de gestão econômica: uma proposta de integração conceitual. Tese (Livre-Docência) - FEA/USP. São Paulo, 1995.

Um modelo de sistema de informação contábil para mensuração do desempenho econômico das atividades empresariais. Caderno de EstudosFIPECAFI. № 4, março, 1992, p. 17.

HENDRICKSEN, Eldon S. \& VAN BREDA, Michael F. Accounting theory. Chicago: Irwin, 1992.

IUDÍCIBUS, Sérgio de. Teoria da Contabilidade. 5ª edição. São Paulo: Atlas, 1997.

JOHNSON, Thomas H. \& KAPLAN, Robert S. Relevance lost. Boston, Massachusetts: Harvard Business School Press, 1987.

LITTLETON, A. C. \& ZIMMERMAN, V. K. Accounting theory: continuity and change. Englewood Cliffs: Prentice-Hall, 1962.

MARTINS, Eliseu. Contribuição à avaliação do ativo intangível. Tese (Doutoramento)-FEAIUSP.São Paulo, 1972.

MAURO, Carlos Alberto. Preço de transferência baseado no custo de oportunidade: um instrumento para a promoção da eficácia empresarial. Dissertação (Mestrado) - FEA/USP. São Paulo, 1991.

MOSIMANN, Clara P. et al. Controladoria: seu papel na administração de empresas. Florinópolis: Editora da UFSC, 1993.
PARISI, Cláudio, et al. Modelo de identificação e acumulação de resultado sob a ótica do Gecon. Caderno de Estudos-FIPECAFI, v. 9, № 15, páginas 9-21, janeiro/junho, 1997.

PARISI, Cláudio. Uma contribuição ao estudo de modelos de identificação e acumulação de resultados. Dissertação (Mestrado) - FEA/USP. São Paulo, 1995.

PEREIRA, Carlos Alberto. Estudo de um modelo de avaliação de desempenhos para gestão econômica. Dissertação (Mestrado) - FEA/USP. São Paulo, 1993.

Ambiente Empresa, Gestão e Eficácia. In Catelli, A. (org.) Controladoria: uma abordagem de Gestão Econômica - GECON . São Paulo: Atlas, 1999.

PHILIPS, Edward G. The acretion concept of income. The Accounting Review, janeiro, 1963.

RAMOS, Alkíndar de Toledo. O problema da amortização de bens depreciáveis e as necessidades administrativas das empresas. Tese (Doutorado) - FEA/ USP. São Paulo, 1968.

REIS, Ernando A. Aspectos da depreciação de ativos sob a ótica da Gestão Econômica. Dissertação (Mestrado) - FEA/USP. São Paulo, 1997.

SANTOS, Edilene S. \& PONTE, Vera. Gestão Econômica: um modelo para a integração sistêmica da empresa. In: Anais do V Congresso Brasileiro de Gestão Estratégica de Custos. v. 2, páginas 705-721. Fortaleza, set, 1998.

. Modelo de decisão em Gestão Econômica. In: Caderno de Estudos/FIPECAFI. v. 10, no 19, páginas 43-56, set./dez., 1998.

SANTOS, Edilene S. Objetividade x relevância: o que o modelo contábil deseja espelhar? Caderno de EstudosFIPECAFI, v. 10, oㅜ18, páginas 9-19, maio/agosto, 1998.

VASCONCELOS, Marco T. C. O processo de gestão de finanças sob a ótica da gestão econômica. Dissertação (Mestrado) - FEA/USP. São Paulo, 1994.

WOMACK, James P. \& JONES, Daniel T. A mentalidade enxuta nas empresa. Rio de Janeiro: Campus, 1998. 